\title{
Adverse reactions in leprosy patients who underwent dapsone multidrug therapy: a retrospective study
}

This article was published in the following Dove Press journal:

Clinical Pharmacology:Advances and Applications

29 June 2017

Number of times this article has been viewed

\author{
Sanjeev Guragain' \\ Namrata Upadhayay ${ }^{2}$ \\ Bishwa Mohan Bhattarai ${ }^{3}$ \\ 'Department of Pharmacology, \\ Gandaki Medical College Teaching \\ Hospital and Research Centre, \\ Lekhnath, ${ }^{2}$ Department of Physiology, \\ Gandaki Medical College Teaching \\ Hospital and Research Centre, \\ Lekhnath, ${ }^{3}$ Dermatology Department, \\ Green Pastures Hospital and \\ Rehabilitation Centre, Pokhara, Nepal
}

Objective: To investigate the occurrence and clinical characteristics of dapsone-related adverse drug reactions (ADRs) among leprosy patients who underwent multidrug therapy (MDT) from 2010 to 2013 in the western region of Nepal.

Methods: A retrospective review was carried out in the rehabilitation center. Data were collected from the record files of the hospital.

Results: From 2010 to 2013, there were 18 patients reported to have dapsone ADRs, with an occurrence rate of $0.82 \%$ in the 4 -year duration. The maximum incidence of ADRs $(1.043 \%)$ was in 2010 and the minimum incidence of ADRs (0.26\%) was in 2013. Among two types of bacterial infections, $94.44 \%$ were of multibacillary and $5.56 \%$ were of paucibacillary type. The age range of patients with dapsone ADRs was 11-68 years. The male-to-female ratio was 1.25. The onset of dapsone ADRs after taking MDT was within a minimum of 3 weeks and a maximum of 21 weeks. There were $14(77.77 \%)$ patients who presented with jaundice, 8 (44.44\%) with exfoliative dermatitis, $5(27.77 \%)$ with hemolytic anemia and $4(22.22 \%)$ with fever and headache. The rare side effects $(5.5 \%)$ found were agranulocytosis or toxic epidermal necrolysis. Three patients were cured; some were still on the treatment. Four patients died with dapsone ADRs.

Conclusion: The common dapsone ADRs present in leprosy patients were jaundice, exfoliative dermatitis and hemolytic anemia in MDT-treated patients. Patients could be cured by managing the dapsone ADRs effectively on time. Some patients may die of dapsone ADRs if clinicians fail to manage the side effects on time.

Keywords: dapsone, dermatitis, anemia, minocycline, ofloxacin

\section{Introduction}

Leprosy is a chronic granulomatous disease caused by Mycobacterium leprae, which can lead to cutaneous and neurological manifestations. Multidrug therapy (MDT) is used for the treatment of leprosy patients. Major drugs of choice are rifampicin, clofazimine and dapsone. ${ }^{1}$ According to the World Health Organization, dapsone is administered at a dose of $100 \mathrm{mg}$ /day for 12 months in multibacillary and for 6 months in paucibacillary forms of leprosy.

Dapsone is considered to be one of the safest drugs for treating leprosy patients. ${ }^{1}$ The adverse drug reaction (ADR) resulting from intake of dapsone is considered the dapsone reaction. There are many adverse effects of dapsone in MDT-treated patients. The most common reactions are allergies, such as itchy rash and blisters, exfoliative dermatitis, hemolytic anemia, jaundice, methemoglobinemia and dapsone syndrome., ${ }^{2,3}$ Among these, clinically severe (emerging) adverse reactions of dapsone in MDT are dapsone
Correspondence: Sanjeev Guragain Department of Pharmacology, Gandaki Medical College Teaching Hospital and Research Centre, Rittepani, PokharaLekhnath, 33700, Kaski, Nepal Tel +9779849180852 Email sanjeevguragain@gmail.com 
hypersensitivity syndrome (DHS), hemolytic anemia, methemoglobinemia ${ }^{4}$ and peripheral neuropathy with motor deficits. ${ }^{5}$

Agranulocytosis is a rare ADR of dapsone. ${ }^{6}$ It has been reported that agranulocytosis occurs in $0.23-0.42 \%$ of dermatitis herpetiformis patients treated with dapsone. ${ }^{7}$ The other rare effects of dapsone are bone marrow suppression and peripheral pancytopenia. ${ }^{8}$

It is evident from the literature that there are emerging side effects, such as agranulocytosis, bone marrow suppression, renal failure, etc, in leprosy patients due to the presence of dapsone in the MDT regimen., ${ }^{2,6,8}$ Therefore, we conducted this study to explore the side effects of dapsone in leprosy patients admitted to a rehabilitation center of western Nepal. The objective is to find the side effects (common or rare) and occurrence of dapsone adverse reaction in leprosy patients. Thus, retrospectively, we planned to perform the study on patients treated with MDT.

\section{Methods}

This was a retrospective cross-sectional study. Prior to the study, permission to conduct the study was obtained from the Gandaki Medical College Institute Ethical Committee, Pokhara, Nepal. The committee did not require that written informed consent be obtained from the patients as the identity of patients was not disclosed and data confidentiality was maintained throughout the study. The data were collected from the Green Pastures Hospital and Rehabilitation Centre (GPHRC), Pokhara. It is a tertiary care hospital in the western region of Nepal and one of the major rehabilitation centers for leprosy patients in Nepal.

\section{Screening of patients}

We screened all the patients admitted in GPHRC over a period of 4 years (2010-2013) for dapsone-related ADRs. We reviewed the types of treatment, doses of drugs, dapsonerelated adverse reactions and types of management undertaken for leprosy patients with dapsone ADRs.

\section{Dose of MDT}

The drugs administered to leprosy patients were rifampicin, clofazimine and dapsone: rifampicin at $600 \mathrm{mg}$ once a month; clofazimine at $300 \mathrm{mg}$ once a month and $50 \mathrm{mg}$ daily; and dapsone at $100 \mathrm{mg}$ daily. Dapsone was administered at a dose of $100 \mathrm{mg} /$ day for 12 months in the multibacillary form and for 6 months in the paucibacillary type of leprosy.

\section{Inclusion and exclusion criteria}

Among the different types of treatment, in this study, we included those patients having dapsone-related ADRs when they were on MDT therapy. Patients with local infections and those suffering from other illnesses, such as diabetes mellitus, hypertension, rheumatoid arthritis and rheumatic fever, were excluded from the study.

Parameters/variables included in the study were as follows:

1. Total number of patients admitted (2010-2013): Data were reviewed for 4 years' duration, and the number of patients admitted to the hospital was noted from the records of the hospital.

2. General characteristics of patients: Age and sex were documented from the records.

3. Types of leprosy: Multibacillary or paucibacillary

4. Occurrence of dapsone-related ADRs: Time of onset of dapsone syndrome was noted and occurrence of dapsone ADRs was calculated from the selected year of the study.

5. Duration of the treatment with MDT: The duration of treatment of leprosy patients with MDT was reviewed and noted from the file. Additionally, different types of dapsone syndrome were documented from the records of the hospital.

Along with the aftorementioned variables, we noted down the time of onset of dapsone-related ADRs, with their bacterial index. Common and rare side effects due to MDT were also documented.

\section{Dapsone removal from the plan of the treatment after appearance of dapsone ADRs}

The number of patients whose MDT drug was stopped after the appearance of the dapsone syndrome was noted down. Additionally, the number of patients whose side effects improved after removal of dapsone from the treatment plan was also documented. The clinical intervention for management of ADRs in MDT-administered patients and the number of patients lost to follow-up and death during their treatment were recorded.

After collecting these data, the frequency of appearance of ADRs was calculated using Microsoft Excel 2007. The results are expressed in percentage and frequency distribution (descriptive data).

\section{Results}

Cases of dapsone ADRs in the period 2010-2013, ie, over a period of 4 years, were reviewed. Out of 2205 leprosy patients admitted, there were 18 cases of dapsone ADRs at GPHRC. The occurrence of dapsone ADRs was $0.82 \%$ in 4 years. Out 
of these 18 cases, 10 were males and 8 were females. The onset of symptoms in the treated patients was in the third week of MDT clinical intervention (Table 1).

The maximum incidence of ADRs (1.043\%) was in 2010 , and the minimum incidence of ADRs (0.26\%) was in 2013 (Table 2). Out of 18 cases, 17 were of the multibacillary type (94.44\%) and one was of the paucibacillary type of leprosy (Table 2). Of the 17 multibacillary types, 14 were smear positive and three were smear negative for the bacteriological index (BI). The paucibacillary type was smear negative for the BI (Table 2).

\section{Severe and common ADRs on MDT therapy}

The ADRs to dapsone were normally seen after 3 weeks of intake of dapsone. The severe ADRs to dapsone included DHS and hemolytic anemia (Table 3). The other ADRs to dapsone were exfoliative dermatitis and jaundice. The rare side effects found were agranulocytosis and toxic epidermal necrolysis (TEN) (Table 3). Out of 18 cases that were on treatment, three were cured, three were referred to health post, one was lost to follow-up and four patients died (male: two and female: two).

\section{Rare side effects}

For the patient who developed agranulocytosis after MDT, only dapsone was stopped. Both rifampicin and clofazimine were continued as usual. TEN was treated with azathioprine and with supportive care (such as administration of antibiotics) and intravenous fluids (such as normal saline).

\section{Clinical intervention}

In all 18 cases, MDT was stopped on appearance of ADRs, and all the three antileprotic drugs were stopped. The treatment was stopped to identify which drug had caused the symptoms. After the management of jaundice, anemia, exfoliative dermatitis or any other ADRs due to dapsone, test doses of rifampicin and clofazimine were again given to the patients. On the absence of reappearance of any ADRs in the test dose, rifampicin and clofazimine were continued for the patients. In the cases were ADRs reappeared, patients were changed to the second-line drugs, ie,

Table I General characteristics of patients and onset of dapsone ADRs $(\mathrm{N}=18)$

\begin{tabular}{|c|c|}
\hline Variables & Values \\
\hline Age range & $1 \mathrm{I}-68$ years \\
\hline $\operatorname{Sex}(n)$ & Male: 10, female: 8 \\
\hline \multirow[t]{3}{*}{ Dose and duration of MDT for adults (WHO guidelines for multibacillary type) } & Rifampicin: $600 \mathrm{mg}$ once a month, \\
\hline & Clofazimine: $300 \mathrm{mg}$ once a month and $50 \mathrm{mg}$ daily \\
\hline & Dapsone: $100 \mathrm{mg}$ daily for 12 months \\
\hline \multirow[t]{2}{*}{ Dose and duration of MDT for adults (WHO guidelines for paucibacillary type) } & Rifampicin: $600 \mathrm{mg}$ once a month \\
\hline & Dapsone: $100 \mathrm{mg}$ daily for 6 months \\
\hline \multirow{3}{*}{$\begin{array}{l}\text { Dose and duration of MDT for children (aged I0-14 years: WHO guidelines for } \\
\text { multibacillary type) }\end{array}$} & Rifampicin: $450 \mathrm{mg}$ once a month \\
\hline & Clofazimine: $150 \mathrm{mg}$ once a month and $50 \mathrm{mg}$ every other day \\
\hline & Dapsone: $50 \mathrm{mg}$ daily for 12 months \\
\hline \multirow{2}{*}{$\begin{array}{l}\text { Dose and duration of MDT for children (aged I0-14 years: WHO guidelines for } \\
\text { paucibacillary type) }\end{array}$} & Rifampicin: $450 \mathrm{mg}$ once a month \\
\hline & Dapsone: $50 \mathrm{mg}$ daily for 6 months \\
\hline Onset of symptoms of dapsone ADRs & $3-21$ weeks \\
\hline
\end{tabular}

Abbreviations: ADR, adverse drug reaction; MDT, multidrug therapy; WHO, World Health Organization.

Table 2 Incidence of dapsone ADRs in each year (2010-2013) by treatment method and $\mathrm{BI}$

\begin{tabular}{|c|c|c|c|c|c|c|}
\hline Year & $\begin{array}{l}\text { Patients } \\
\text { admitted (n) }\end{array}$ & $\begin{array}{l}\text { Patients with } \\
\text { dapsone ADRs (\%) }\end{array}$ & $\begin{array}{l}\text { Treatment } \\
\text { method }\end{array}$ & $\begin{array}{l}\text { Patients by } \\
\text { method (n) }\end{array}$ & BI & $\begin{array}{l}\text { Patients } \\
\text { by BI (n) }\end{array}$ \\
\hline 2010 & 575 & $6(1.043)$ & Multibacillary & 17 & Bl with I+ & 2 \\
\hline 2011 & 593 & $5(0.843)$ & Paucibacillary & I & Bl with $2+$ & I \\
\hline 2012 & 645 & $6(0.93)$ & Drug reaction management & I & Bl with $3+$ & I \\
\hline \multirow[t]{5}{*}{2013} & 392 & I (0.26) & Minocycline and ofloxacin & 2 & Bl with 4+ & 7 \\
\hline & & & Rifampicin and clofazimine & 4 & Bl with $5+$ & 2 \\
\hline & & & Referred to health post & 3 & Bl with $6+$ & I \\
\hline & & & Lost to follow-up or death & I-lost & $\mathrm{BI}$ negative & 4 \\
\hline & & & & I-died & & \\
\hline
\end{tabular}

Abbreviations: $A D R$, adverse drug reaction; $\mathrm{BI}$, bacterial index. 
Table 3 Side effects presented in 18 patients after treatment with multidrug therapy

\begin{tabular}{lll}
\hline Common and rare side effects & Patients (n) & Patients (\%) \\
\hline Jaundice (along with other symptoms) & 14 & 77.77 \\
Exfoliative dermatitis (mainly in face and all over the body), along with other symptoms & 8 & 44.44 \\
Hemolytic anemia (along with the above symptoms) & 5 & 27.77 \\
Fever and headache & 4 & 22.22 \\
Blisters over the body & 2 & 11.11 \\
Skin rashes & 2 & 11.11 \\
Agranulocytosis only (no other symptoms) & 1 & 5.5 \\
Toxic epidermal necrolysis & 1 & 5.5 \\
\hline
\end{tabular}

ofloxacin $(400 \mathrm{mg})$ twice a day and minocycline $(100 \mathrm{mg})$ once a day (Table 2).

\section{Management for exfoliative dermatitis}

Cetirizine was given as an antiallergic drug. Cetirizine was generally given for 1-2 weeks. Coconut oil massage over the exfoliation region of the body was done. By observing the severity of the disease in some patients, hydrocortisone was given intravenously for about 4 days. Prednisolone was given in all cases because it has a role in the reduction of the symptoms of both lepra reaction and exfoliative dermatitis.

\section{Management of jaundice}

Jaundice was treated symptomatically with vitamin B complex, lactulose, Hepa-Merz ${ }^{\circledR}$ (detoxicant-hepatoprotector) and Liv-52 tablet for 4-10 weeks. Liv-52 is an ayurvedic medicine and a hepatoprotective herbal-mineral remedy to improve liver function. These drugs were given until the symptoms of jaundice subsided.

\section{Management of anemia}

Iron tablets and multivitamins were given for 4-10 weeks to patients until the symptoms of anemia subsided. In severe anemic patients, based on the blood hemoglobin concentration, whole blood transfusion was done. Two patients were transfused with two pints of whole blood due to low hemoglobin level (6.4\%) in their blood. One of them expired due to severe anemia even after blood transfusion.

\section{Discussion}

This study was carried out retrospectively to explore the adverse reactions of dapsone administration in leprosy patients treated with MDT. The objective was to determine the side effects (common or rare) and the occurrence of dapsone reaction in leprosy patients. We reviewed 4 years' data from a leprosy rehabilitation center in the western region of Nepal.

We found that the occurrence rate of dapsone ADRs was $0.816 \%$ in 4 years. In a previous review, ${ }^{9}$ the prevalence rate of total hypersensitivity reaction due to dapsone was reported to be $1.4 \%$. In our study, in terms of the two types of bacterial infections, $94.44 \%$ was of multibacillary and the remainder was of the paucibacillary type. Out of 18 cases, 14 showed positive smear for the BI. Many years ago, it was mentioned that the incidence of hypersensitivity reactions to dapsone was high (3.6\%) due to MDT use in leprosy patients..$^{10}$ Now after some years, the incidence of dapsone hypersensitivity seems to be on the decline in many countries. In Nepal, ${ }^{11}$ it was $2 \%$ in 2007 and $0.26 \%$ in 2013 (this study); in China, it was $1 \%$ in $2012 .{ }^{4}$ It has been predicted in 2004 that the annual decline in incidence of leprosy ranges from $2 \%$ to $12 \%$ with MDT treatment along with BCG vaccination program to eliminate leprosy from the world. ${ }^{12}$ As ADR incidence was declining in our study, in some aspects, the result supports the use of MDT in leprosy for its elimination.

In this study, we found that the drug reactions to dapsone were normally observed after 3 weeks of MDT intake. The side effects can be categorized into two kinds, pharmacological and idiosyncratic ones. The former type was related to the dosage of the drug and includes methemoglobinemia, hemolytic anemia, etc. The latter was not related to the dosage but to cell-mediated hypersensitivity (DHS) and ranged from mild cutaneous manifestations, such as exfoliative dermatitis, to jaundice, nephritis, renal failure and Stevens-Johnson syndrome etc. ${ }^{13}$ In this study, the ADRs to dapsone included exfoliative dermatitis (44.44\%), hemolytic anemia (27.77\%) and jaundice $(77.77 \%$ ), with $22.22 \%$ incidence of fever and headache. In China, $88.9 \%$ had skin lesions and fever, with $63.5 \%$ showing hepatic damage. ${ }^{4}$ In a report, it has been mentioned that hemolytic anemia was one of the common side effects seen in leprosy patients treated with dapsone, ${ }^{3}$ which was similar to our result. However, contrary to others, we did not find renal failure and nephritis as a common dapsone side effect in MDT-treated patients. ${ }^{14,15}$

To explain the mechanism for hemolytic anemia in leprosy, it has been mentioned that the dapsone used in the MDT regime for leprosy decreases the hematocrit and hemoglobin 
levels due to a low-grade hemolysis, which can result in significant anemia. Further, reports mention that individuals deficient in erythrocyte glucose-6-phosphate dehydrogenase were at high risk of having severe fatal hemolysis due to dapsone. ${ }^{16}$ Probably, dapsone decreases glucose-6-phosphate dehydrogenase enzyme due to which red blood cells breaks down prematurely. The other proposed mechanism was that hydroxylamine, a toxic metabolite of dapsone formed by $N$-hydroxylation, might result in hemolytic anemia and DHS. ${ }^{4}$ We did not find lymphadenopathy as in other studies. Lymphadenopathy due to dapsone was found to be $34.9 \%$ in leprosy patients. ${ }^{4}$ In the same study, seven patients died, with a death rate of $11.1 \%$ due to dapsone hypersensitivity. In our study, out of 18 patients, four patients died due to dapsone ADRs, three patients were cured and some were still on treatment. Out of four patients who died, two expired due to severe anemia and two others expired due to jaundice and severe dapsone syndrome.

In our study, the rare side effects $(5.5 \%)$ found were agranulocytosis and TEN. Agranulocytosis was a rare ADR of dapsone, ${ }^{6}$ but a severe and unpredictable idiosyncratic reaction. It has been reported that agranulocytosis occurs in $0.23-0.42 \%$ of dermatitis herpetiformis patients treated with dapsone. ${ }^{7}$ Agranulocytosis led to perianal abscess and death of a Japanese woman due to septic shock. ${ }^{17}$ In the majority of cases, agranulocytosis occurrence was due to sensitization to the drug, which depresses the formation of granulocytes in the bone marrow. This increases the chance or vulnerability for more infection in the patients.

In this study, the supportive treatment used to improve the ADRs was to stop the use of MDT first on appearance of ADRs. Later, symptomatic treatment was done in all the patients by fluid and electrolyte balance, nutritional support, antibiotics, skin care (coconut oil massage, Vaseline application), administration of vitamin B complex and lactulose, and so on. After the management of jaundice, anemia, exfoliative dermatitis or any other ADRs of dapsone, test doses of rifampicin and clofazimine were again given. Earlier, rifampicin and clofazimine were reported to appear to be satisfactory treatments for both paucibacillary and multibacillary patients after stopping the use of dapsone (due to ADRs) in the MDT treatment. ${ }^{11}$ In this study, on the absence of reappearance of ADRs on test dose, rifampicin and clofazimine were continued in the patients. However, in the cases where ADRs reappeared after test dose, patients were changed to the second-line treatment with ofloxacin and minocycline. They were still on the treatment.
The three major drugs used in MDT are rifampicin, clofazimine and dapsone. ${ }^{1}$ Among these drugs, dapsone is a sulfone drug that inhibits bacterial dihydrofolic acid synthesis and suppresses the growth of bacteria. ${ }^{18,19}$ Rifampicin acts by binding to DNA-dependent RNA polymerase to form a stable drug-enzyme complex and suppresses chain formation during RNA synthesis in the bacteria. However, the mechanism of action of clofazimine is not well understood. Among these drugs, dapsone shows high ADRs in MDT-treated leprosy patients. ${ }^{2}$ We also found similar results. The common ADRs of the MDT regime (rifampicin, clofazimine and dapsone) include hemolytic anemia, hepatic abnormalities, gastrointestinal manifestations, leukopenia, skin reactions, etc. ${ }^{20}$ Some authors have reported that rifampicin causes cutaneous eruptions, thrombocytopenic purpura, hepatitis, a flu-like syndrome, hemolytic anemia, shock, respiratory insufficiency and acute renal failure. ${ }^{2}$ Clofazimine is most active when it is administered daily and is considered nontoxic in the usual dosage with no identified side effects. ${ }^{2}$

\section{Conclusion}

The common side effects in leprosy patients of Nepal due to MDT treatment were jaundice, exfoliative dermatitis and hemolytic anemia. Few patients died due to jaundice, severe anemia and dapsone syndrome. The rare side effects found were agranulocytosis and TEN. The ADRs could be managed by stopping the use of dapsone on appearance of drug reactions. In addition to this, rifampicin and clofazimine with other supportive treatment can be continued in the patients. However, on reappearance of ADRs, ofloxacin and minocycline could be given to the patients as an alternative treatment. Thus, clinicians should find out the adverse reaction of dapsone as early as possible and manage it quickly and on-time with adequate and appropriate treatment.

\section{Acknowledgment}

We acknowledge the management and staff of the Green Pastures Hospital and Rehabilitation Centre, Pokhara, Nepal, for their kind support during the data collection in the hospital.

\section{Author contributions}

All authors contributed toward data analysis, drafting and critically revising the paper, gave final approval of the version to be published, and agree to be accountable for all aspects of the work. 


\section{Disclosure}

The authors report no conflicts of interest in this work.

\section{References}

1. WHO [webpage on the Internet]. Leprosy Elimination. 2015. Available from: http://www.who.int/lep/mdt/regimens/en/. Accessed September 24, 2015.

2. Deps PD, Nasser S, Guerra P, Simon M, Birshner Rde C, Rodrigues LC. Adverse effects from multi-drug therapy in leprosy: a Brazilian study. Lepr Rev. 2007;78:216-222.

3. Deps P, Guerra P, Nasser S, Simon M. Hemolytic anemia in patients receiving daily dapsone for the treatment of leprosy. Lepr Rev. 2012;83:305-307.

4. Tian W, Shen J, Zhou M, Yan L, Zhang G. Dapsone hypersensitivity syndrome among leprosy patients in China. Lepr Rev. 2012;83:370-377.

5. McCarty M. How clinically relevant is dapsone-related peripheral neuropathy? An overview of available data with emphasis on clinical recognition. J Clin Aesthet Dermatol. 2010;3(3):19.

6. Bhat RM, Radhakrishnan K. A case report of dapsone induced agranulocytosis in an Indian mid-borderline leprosy patient. Lepr Rev. 2003;74:167-170.

7. Hornsten P, Keisu M, Wiholm BE. The incidence of agranulocytosis during treatment of dermatitis herpetiformis with dapsone as reported in Sweden, 1972 through 1988. Arch Dermatol. 1990;126:919-922.

8. Grace M. An unusual case of dapsone syndrome. Indian Dermatol Online J. 2011;2(2):88-90.

9. Lorenz M, Wozel G, Schmitt J. Hypersensitivity reactions to dapsone: a systematic review. Acta Derm Venereol. 2012;92:194-199.

10. Richardus JH, Smith TC. Increased incidence in leprosy of hypersensitivity reactions to dapsone after introduction of multidrug therapy. Lepr Rev. 1989;60:267-273.
11. Sapkota BR, Shrestha K, Pandey B, Walker SL. A retrospective study of the effect of modified multi-drug therapy in Nepali leprosy patients following the development of adverse effects due to dapsone. Lepr Rev. 2008;79(4):425-428.

12. Meima A, Smith WCS, Van OortmarssenI GJ, Richardus JH, Habbema JDF. The future incidence of leprosy: a scenario analysis. Bull World Health Organ. 2004;82(5):373-380.

13. Alldy EJ, Barnes J. Toxic effects of diaminodiphenyl sulphone in the treatment of leprosy. Lancet. 1951;2:205-206.

14. Alves-Rodrigues EN, Ribeiro LC, Dióz Silva M, Takiuchi A, Fontes CJ. Dapsone syndrome with acute renal failure during leprosy treatment: case report. Braz J Infect Dis. 2005;9(1):84-86.

15. Bucaretchi F, Vicente DC, Pereira RMI, Tresoldi AT. Dapsone hypersensitivity syndrome in an adolescent during treatment during of leprosy. Rev Inst Med Trop Sao Paulo. 2005;46(6):331-334.

16. Grossman S, Budinscki R, Jollow D. Dapsone-induced hemolytic anemia: role of glucose-6-phosphatodehydrogenase in the hemolytic response of rat erythrocytes to N-hydroxydapsone. J Pharmacol Exp Ther. 1995;272:870-877.

17. Kobe Y, Setoguchi D, Kitamura N. Dapsone-induced agranulocytosis leading to perianal abscess and death: a case report. J Med Case Rep. 2011;5:107.

18. WHO [webpage on the Internet]. Guide to Elimination. 2007. Available from: http://www.who.int/lep/resources/guides/en/index.html. Accessed January 10, 2010.

19. Jopling WH. References to 'side- effects of antileprosy drugs in common use'. Lepr Rev. 1985;56:61-70.

20. Singh H, Nel B, Dey V, Tiwari P, Dulhani N. Adverse effects of multidrug therapy in leprosy, a two years' experience (2006-2008) in tertiary health care centre in the tribal region of Chhattisgarh state (Bastar, Jagdalpur). Lepr Rev. 2011;82:17-24.
Clinical Pharmacology: Advances and Applications

\section{Publish your work in this journal}

Clinical Pharmacology: Advances and Applications is an international, peer-reviewed, open access journal publishing original research, reports, reviews and commentaries on all areas of drug experience in humans. The manuscript management system is completely online and includes a very quick and fair peer-review system, which is all easy to use.
Dovepress

Visit http://www.dovepress.com/testimonials.php to read real quotes from published authors. 